\title{
Anti-FGFR3 Monoclonal Antibody MFGR1877S
}

National Cancer Institute

\section{Source}

National Cancer Institute. Anti-FGFR3 Monoclonal Antibody MFGR1877S. NCI Thesaurus.

Code C116863.

A human monoclonal antibody against the fibroblast growth factor receptor type 3 (FGFR3), with potential antineoplastic activity. Upon administration, the anti-FGFR3 antibody MFGR1877S binds to and inhibits FGFR3, which may result in the inhibition of both FGFR3 phosphorylation and FGFR3-mediated signal transduction pathways. This results in the inhibition of cell proliferation and the induction of cell death in FGFR3expressing tumor cells. FGFR3, upregulated or mutated in many tumor cell types, is a receptor tyrosine kinase, and plays a key role in tumor cell proliferation. 